\title{
Outcome of Primary Prevention Implantable Cardioverter Defibrillator Therapy According to New York Heart Association Functional Classification
}

Rui Providência ${ }^{\mathrm{a}, \mathrm{b} *}$ MD PhD, Serge Boveda ${ }^{\mathrm{a}}$ MD, Pascal Defaye ${ }^{\mathrm{c}}$ MD PhD, Oliver Segal ${ }^{\mathrm{b}}$ MD, Vincent Algalarrondo ${ }^{\mathrm{d}}$ MD PhD, Nicolas Sadoul ${ }^{\mathrm{e}}$ MD PhD, Pier Lambiase ${ }^{\mathrm{b}, \mathrm{f}} \mathrm{PhD}$, Olivier Piot $^{\mathrm{g}}$ MD, Didier Klug ${ }^{\mathrm{h}}$ MD PhD, Marie-Cecile Perier ${ }^{\mathrm{i}}$ MS, Abdeslam Bouzeman ${ }^{\mathrm{a}}$ MD, Sergio Barra ${ }^{\mathrm{j}}$ MD, Daniel Gras $^{\mathrm{k}}$ MD, Laurent Fauchier ${ }^{1}$ MD PhD, Pierre Bordachar ${ }^{\mathrm{m}}$, MD PhD, Dominique Babutyl, MD PhD, Jean-Claude Deharo ${ }^{\mathrm{n}}, \mathrm{MD} \mathrm{PhD}$, Christophe Leclercq ${ }^{\circ}, \mathrm{MD} \mathrm{PhD}$,

Eloi Marijon ${ }^{\mathrm{i}} \mathrm{MD} \mathrm{PhD}$; on Behalf of the DAI-PP Investigators

Running title: NYHA and Primary Prevention ICDs

From:

${ }^{\mathrm{a}}$ Clinique Pasteur, Toulouse, France

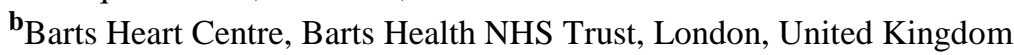

${ }^{\mathbf{c}} \mathrm{CHU}$ Michallon, Grenoble, France

${ }^{\mathbf{d}}$ CHU Antoine Béclère, Clamart, France

${ }^{\mathbf{e}} \mathrm{CHU}$ Brabois, Nancy, France

f Institute of Cardiovascular Sciences, University College of London, London, United Kingdom

gentre Cardiologique du Nord, Saint Denis, France

${ }^{\text {h}}$ CHRU Lille, Lille, France

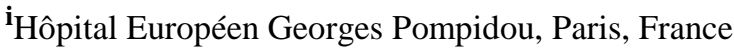

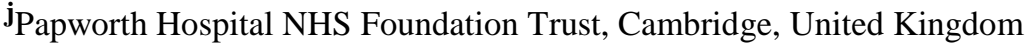

${ }^{\mathbf{k}}$ Nouvelles Cliniques Nantaises, Nantes, France

${ }^{\mathbf{l}} \mathrm{CHU}$ Trousseau, Tours, France

${ }^{\mathbf{m}_{\mathrm{CHU}}}$ Haut Lévêque, Bordeaux, France

${ }^{n_{C}} \mathrm{CHU}$ La Timone, Marseille, France

${ }^{\mathbf{0}} \mathrm{CHU}$ Pontchaillou, Rennes, France

Running Title: NYHA and Primary Prevention ICDs

Abbreviations: CRT - Cardiac Resynchronization Therapy; DAI-PP - Défibrillateur Automatique Implantable-Prévention Primaire; ICD - implantable cardioverter-defibrillator; LVEF - Left Ventricular Ejection Fraction; NYHA - New York Heart Association. 
We aimed to assess if the outcome of primary prevention implantable cardioverter defibrillators (ICDs) without cardiac resynchronization therapy (CRT) is dependent on New York Heart Association (NYHA) class. Among the participants of Défibrillateur Automatique Implantable-Prévention Primaire (DAI-PP;NCT01992458) multicenter cohort study, 155 patients in NYHA class I, 504 in NYHA class II and 188 in NYHA class III had a QRS width $<120 \mathrm{~ms}$ and were implanted with an ICD without CRT, and thus were eligible for the purpose of this analysis. Total and specific mortalities, and the incidence of appropriate therapies were

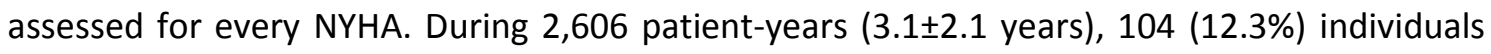
died and 188 (22.2\%) experienced appropriate therapies. After adjustment, overall mortality increased with NYHA class (adjusted $H R=1.63,95 \% \mathrm{Cl} 1.11-2.41, \mathrm{P}=0.014$ ), driven by an increase in cardiovascular death. Conversely, incidence of appropriate ICD intervention was comparable among the 3 NYHA groups (NYHA class I 7.43, NYHA class II 7.91 and NYHA class III 12.10 per 100 patient-years; $H R=1.19,95 \% \mathrm{Cl} 0.89-1.59, P=0.231$ ). Incidence of ICD-unresponsive sudden death was very low and also comparable (NYHA class I 0.22, NYHA class II 0.36, and NYHA class III 0.83 per 100 patient-years; $(H R=6.34,95 \% \mathrm{Cl} 0.32-124.49, \quad P=0.224)$. No significant differences were observed in the other specific modes of death. In conclusion, even though patients in NYHA class III have higher overall mortality, they experience a comparable incidence of appropriate ICD therapies. The low incidence of ICD-unresponsive sudden death in all assessed NYHA classes also supports the efficacy of ICDs, irrespective of NYHA class.

Key-words: heart failure; appropriate therapy; competing risk; sudden death. 


\section{Background}

Implantable cardioverter defibrillators (ICDs) are a proven lifesaving therapy and their use in the primary prevention setting is supported by Guidelines [1-2]. According to these, ICDs meet a class I recommendation, level of evidence A, for primary prevention in individuals on optimal medical therapy who are at least 40 days post-myocardial infarction and with a left ventricular ejection fraction (LVEF) $\leq 35 \%$, and New York Heart Association functional class (NYHA) II or III symptoms. For non-ischemic cardiomyopathy, there is a class I recommendation for individuals with LVEF $\leq 35 \%$ and NYHA II or III symptoms, but level of evidence B only [1, 2]. However, while evidence supporting a $30 \%-35 \%$ LVEF cut-off and a 40 -day time-interval post-acute myocardial infarction is strong and based on the results of randomized controlled trials [3-6], the same cannot be said for using NYHA class III, as sub-analyses of the SCD-HeFT [3] and MADIT-II [4] trials failed to confirm a mortality benefit of primary prevention ICD in this group of patients. This may imply a lack of benefit in these individuals due to a higher prevalence of comorbidity (i.e. competing-risk situation), or as a result of ICD-unresponsive sudden cardiac death. We aimed to address mortality (with cause of death analysis), appropriate ICD interventions and complications, and their possible interference with NYHA functional classes in a large cohort of "real life" patients.

\section{Methods}

Among the participants of the DAI-PP cohort (Défibrillateur Automatique ImplantablePrévention Primaire; NCT01992458), 847 presented with narrow QRS, and were implanted with single or dual chamber ICDs: 155 patients in NYHA class I, 504 in NYHA class II and 188 in NYHA class III were eligible for the purpose of this analysis. Briefly, DAI-PP included patients who were $\geq 18$ years of age at the time of ICD implantation. Overall, between 2002 and 2012, all patients with ischemic or non-ischemic cardiomyopathy, stable on maximally tolerated medical therapy, implanted with an ICD (biventricular, single or dual chamber) in the setting of 
primary prevention in 12 French reference centers were considered and enrolled in the DAI-PP follow-up program. All other patients were classified as suffering from non-ischemic cardiomyopathy.

Exclusion criteria included secondary prevention ICD recipients, those without structural heart disease (including channelopathies) or other types of structural heart disease (e.g. hypertrophic cardiomyopathy, non-compaction and arrhythmogenic right ventricular cardiomyopathy). We selected only patients with a QRS width $<120 \mathrm{~ms}$ implanted with single or dual chamber ICDs for this particular analysis, as evidence of benefit for patients with QRS width $>120 \mathrm{~ms}$ and heart failure symptoms already exists and mandates CRT-D implantation [7, 8]. Only patients with NYHA class I-III symptoms on optimal medical therapy are eligible for primary prevention non-CRT ICDs, according to guidelines [1, 2], and therefore patients with NYHA class IV symptoms were excluded.

The study was funded by public sources, including the French Institute of Health and Medical Research (INSERM) and the French Society of Cardiology, and was coordinated by Clinique Pasteur, Toulouse and the Paris Cardiovascular Research Center, European Georges Pompidou Hospital, Paris, in France. The study complied with the Declaration of Helsinki, and the data file of the DAI-PP study was declared to and authorized by the French data protection committee (Commission Nationale Informatique et Liberté, CNIL).

All variables at the time of the procedure were defined and categorized according to the literature or common practice. In addition to NYHA functional class, assessed by the local DAI-PP investigator at the time of device implantation, we collected the aetiology of the underlying heart disease (ischemic or dilated cardiomyopathy). Estimated glomerular filtration rate (eGFR), was estimated using the Cockroft-Gault formula and categorized into 2 categories ( $\geq 60$ and $<60 \mathrm{~mL} / \mathrm{min}$ ). Atrial fibrillation (AF) was defined as a history of AF (paroxysmal or persistent), documented on standard ECG or 24-hour Holter monitoring. Co-morbidities were 
systematically collected: cancer, chronic obstructive pulmonary disease, chronic renal failure, chronic liver disease, history of transient ischemic neurological attack, and others (including diabetes mellitus). Device programming was left to the implanting/managing physician's discretion.

Follow-up information was obtained from appointments every 4-6 months for device evaluation, according to French guidelines [9]. The different endpoints included occurrence of appropriate therapies, early complications, inappropriate shocks and overall and specific mortalities.

Device interrogation data were checked by local investigators for appropriate and inappropriate ICD therapies. Appropriate ICD therapy was defined as an episode of ventricular tachycardia/ventricular fibrillation resulting in a single or multiple shocks and/or antitachycardia pacing for arrhythmia termination. The date of the first appropriate ICD therapy was recorded, and the cumulative number of appropriate therapies. The cause of inappropriate shock(s) was collected. Adjudication of therapy type (appropriate or inappropriate) was undertaken by the local investigator.

Early complications (defined as those appearing in the first 30 days after device implantation) included lead dysfunction, bleeding or hematoma, sepsis, cardiac tamponade, pneumothorax and death.

Mortality data were obtained from the hospital or the general practitioner, and were systematically controlled through the National Institute of Statistics Economical Studies (INSEE). Causes of death were obtained from the investigators and/or by the French Center on Medical Causes of Death (CépiDc-INSERM). The CépiDc-INSERM is a public, academic institution focused on the analysis of circumstances and causes of death based on death certificate and medical records. Causes of deaths were classified according to the International Classification of Diseases (10 ${ }^{\text {th }}$ Revision). This information was reviewed by two investigators 
and causes of death adjudicated after consideration of all available information, and according to the following pre-specified groups: cardiovascular (including progressive heart failure death, stroke), non-cardiovascular, ICD-unresponsive sudden cardiac death (SCD) (arrhythmic or nonarrhythmic whenever assessment possible), ICD-related death, as well as unknown when the quality of the information could not allow investigators to appropriately identify cause of death. Overall, cause of death assessment was possible among 91 out of 104 deceased patients (87.5\%).

Preparation of this report was in accordance with the Strengthening the Reporting of Observational Studies in Epidemiology (STROBE) statement for reporting of observational studies [10].

Comparisons were performed across the different NYHA functional class strata. Chisquare was used for comparison of nominal variables and Student's t-test for continuous variables; the Levene's test was used to check the homogeneity of variance; when appropriate non-parameteric equivalent, Mann-Whitney test, was employed. When baseline differences were present, adjustment was performed. Results with $p<0.05$ were regarded as significant.

We compared the adjusted outcomes of appropriate shock and death across different NYHA class strata by using Cox proportional hazards regression analysis. Hazard-curves were traced for comparison of the occurrence of events among the different NYHA functional classes after adjustment for baseline differences. Univariate Cox Regression and subsequent multivariate Cox Regression (forward likelihood ratio, probability for stepwise $=0.05$ ) was performed for assessment of predictors of mortality and appropriate ICD interventions.

Data was filled into a pre-defined data introduction electronic sheet made available to all participant Centers. After completion of follow-up, data from all Centers was merged and analysed at the Paris Cardiovascular Research Center (Inserm U970, Cardiovascular Epidemiology Unit) using SAS program v9.3 (SAS Institute Inc, Cary, North Carolina). 


\section{Results}

Among the 847 patients who were deemed eligible for analysis, mean age was $59.3 \pm 11.6$ years and $13.0 \%(110)$ were female. AF was present in $15 \%$ of patients and ischemic cardiomyopathy was the most prevalent, accounting for almost $74 \%$ of the sample. Moderate to severe renal impairment (eGFR $<60 \mathrm{ml} / \mathrm{min}$ ) was observed in almost $30 \%$ of patients. The use of single and dual chamber ICDs was equally distributed (Table 1).

No differences were observed with respect to age or gender across the three different NYHA functional classes. However, AF was more prevalent in NYHA III patients, but ischemic cardiomyopathy less prevalent compared to those in NYHA class II. NYHA I and II patients more frequently had no co-morbidities, and those in NYHA II and III frequently had $\geq 2$. Left ventricle ejection fraction decreased as NYHA functional class progressed (Table 1).

Assessment of medication use showed use of furosemide and vitamin-K antagonists was more frequent in NYHA classes II and III (a progressive and significant increase across the three NYHA functional classes). However, amiodarone was used almost twice as much in NYHA class III than those in classes I and II, while beta-blocker use was broadly similar.

During 2,606 patient-years of follow-up (mean of $3.1 \pm 2.1$ years), 188 (22.2\%) individuals experienced at least one appropriate therapy (anti-tachycardia pacing or shocks), with annual incidence rates of $7.43(95 \% \mathrm{Cl} 5.25-10.41), 7.91(95 \% \mathrm{Cl} 6.61-9.44)$, and 12.10 (95\% Cl 9.22-15.72) per 100 patient-years, in NYHA classes I, II, and III, respectively (Table 2). After adjustment for baseline differences among the three NYHA classes, the likelihood of appropriate ICD intervention was comparable ( $\mathrm{HR}=1.19,95 \% \mathrm{Cl} 0.89-1.59, \mathrm{P}=0.231)$ (Figure 1). The percentage of patients with appropriate therapies across the 3 classes was similar, and these occurred at least once in every four or five implanted patients (NNT = 5 in NYHA I, 4.4 in NYHA II, and 4 in NYHA III) (Table 2). The occurrence of inappropriate shocks, complications, and box change as a result of battery depletion was comparable among the three groups. 
Few patients (3.3\%; $n=28)$ were lost to follow-up, either because they had their followup transferred to other centers or moved out of the country. A total of $104(12.3 \%)$ individuals died during follow-up. Mortality progressively increased from 1.73 per 100 (95\% $\mathrm{Cl} 0.88-3.37)$ patient-years in class I, to 3.79 (95\% 2.97-4.82) in class II and 6.87 (95\% 4.93-9.49) in class III (Table II). On multivariate Cox regression, only age ( $\mathrm{HR}=1.03$ per increase in year, $95 \% \mathrm{Cl} 1.01$ 1.05, $\mathrm{P}=0.006), \mathrm{eGFR}<60 \mathrm{ml} / \mathrm{min}(\mathrm{HR}=1.70,95 \% \mathrm{Cl} 1.09-2.65, \mathrm{P}=0.019)$ and NYHA class $(\mathrm{HR}=1.63$ per increase in class, $95 \% \mathrm{Cl} 1.11-2.41, \mathrm{P}=0.014)$ (Figure 1 ), but not appropriate therapies, were independent predictors of mortality.

Incidence of death prior to receiving any appropriate therapy was similar in all NYHA groups: $62.5 \%$ (5 in 8 deaths) in NYHA I patients, 71.0\% (44 in 62 deaths) in NYHA II patients, and $69.7 \%$ (10 out of 33 deaths) in NYHA III patients ( $P=0.889$ ) (Figure $\mathrm{S}-1$ - supplementary material - available online only).

The occurrence of ICD-unresponsive sudden death, ICD-related death, and death from unknown causes was very low and comparable among all groups (all P=N.S.) (Table 2 and Figure 2). The incidence of death from refractory heart failure approximately doubled for every increase in NYHA functional class cohort $(\mathrm{HR}=2.01,95 \% \mathrm{Cl} 1.09-3.71, \mathrm{P}=0.026)$. Noncardiovascular mortality was numerically, but non-significantly, higher in NYHA functional class III patients compared to NYHA I and II.

\section{Discussion}

Our data suggest that even though primary prevention ICD patients in NYHA class III who are not candidates for CRT have higher global mortality than their healthier counterparts in lower NYHA classes, they seem to experience a comparable incidence of appropriate ICD interventions. No excess in inappropriate shocks or early complications was observed in the more symptomatic patients' NYHA class. This suggestion of a comparable net benefit independently of NYHA class was observed in spite of the presence of more severe and 
advanced disease, and more comorbidities in NYHA class III patients. The incidence of death from refractory heart failure doubled for every increase in NYHA functional class. Incidence of ICD-unresponsive sudden death in primary prevention ICD recipients is very low and similar across NYHA class, suggesting that ICD therapy can prevent this outcome as effectively in those with NYHA functional class III symptoms as those with less symptoms. To the best of our knowledge, this is the first cause of death analysis according to NYHA class in a primary prevention ICD setting.

A recent meta-analysis on the therapeutic efficacy of common heart failure interventions according to NYHA status, including trial data only, has suggested that relative mortality reduction with most interventions was independent of baseline NYHA class [11]. However, that did not seem to apply to ICDs, whose efficacy was greater in individuals with lower NYHA (classes I and II vs. classes III and IV). Conversely, these results are challenged by a previous meta-analysis, including non-CRT ICD trials only, which shows no evidence of a tendency for the relative risk reduction to be smaller in patients with severe heart failure [12]. We believe these meta-analyses are difficult to interpret, as they have several caveats: in the first [11], ICD and CRT-D trials are combined, and comparisons are performed which include NYHA class IV individuals, where the use of primary prevention ICDs is debatable; in the second [12], primary and secondary prevention ICD trials were pooled together, mixing two very different subsets of patients with very different inherent risks.

Trials in the pre-ICD era, like the "Metoprolol CR/XL Randomised Intervention Trial in Congestive Heart Failure" (MERIT-HF) have shown that, in patients treated medically, sudden death accounted for the majority of deaths in patients in NYHA classes II and III (64\% and 50\%, respectively) [13]. In the present analysis with patients treated with primary prevention ICDs, sudden cardiac death accounted for only approximately $10 \%$ of all deaths, across all assessed 
NYHA functional classes, clearly indicating a paradigm shift in prognosis for these patients, who now die more frequently due to pump failure or non-cardiac causes.

Other groups have shown that primary prevention ICD patients with more advanced NYHA class have a higher, or at least similar, incidence of appropriate ICD therapies [14-16]. Kreuz et al. [14] and Zareba et al. [15], in 2 studies comprising only non-CRT ICDs recipients, have shown that patients in more advanced NYHA class experience higher rates of appropriate therapies. $\mathrm{Ng}$ and colleagues, in a cohort of primary prevention ischemic cardiomyopathy patients including $62 \%$ with CRT-Ds, found that NYHA class was not a predictor for appropriate interventions [16]. These last results, resemble our own findings, where appropriate therapies occurred at a similar rate, irrespective of NYHA functional class.

Appropriate ICD therapies have previously been associated with increased risk of mortality by other groups [17-19]. However, in this cohort of primary prevention ICD recipients, the occurrence of appropriate therapies was not a predictor of death, even when all NYHA classes were assessed separately. This evidence does not support the view (perhaps pessimistic) that ICD therapy lacks survival benefit in the NYHA class III population. Similarly, even though patients in class III present with a higher prevalence of co-morbidity and may ultimately die from advanced heart failure or other non-cardiac competing causes, these data show that the incidence of sudden death is very low and comparable across all NYHA groups, suggesting ICD therapy prevents sudden death as effectively in NYHA class III patients when compared to healthier patients. It has been previously suggested that patients in more advanced stages of disease, with higher number of comorbidities may potentially be too sick to derive benefit from this lifesaving therapy, and would die irrespective of receiving appropriate therapies [18]. Data from this analysis does not support this hypothesis.

Lastly, NYHA is an established and well-validated predictor of mortality in the ICD population, as observed in our analysis, and its use has been suggested as part of calculating 
risk scores $[20,21]$. However, the causes and mechanisms of death in these patients are not clearly understood, as most studies assessing this issue thus far, do not provide a detailed cause of death analysis. The score proposed by Goldenberg and colleagues, derived from the MADIT-II trial, suggests that individuals in higher NYHA classes may still derive a benefit from ICD therapy, as long as they don't possess two or more additional risk factors, which can lead to death due to non-cardiac competing causes and other comorbidity [20].

This analysis has a number of limitations that should be highlighted. Firstly, device programming was left to the discretion of individual investigators, according to each patient's needs, may have been a source of some inter-individual variability. This factor has been minimized by proposed programming rules particularly based on using high detection windows and not suggesting specific adjustments according to NYHA functional class [9]. Secondly, data was collected only for overall appropriate ICD therapies and not specifically for antitachycardia pacing or shocks. Therefore, a separate analysis cannot be performed for therapy type. Thirdly, no post-mortem ICD interrogation was performed routinely to help confirm mode of death, meaning we do not know the incidence of unsuccessful ICD therapies preceding death. Fourthly, no central adjudication for classification of appropriate and inappropriate therapies was used in this registry. Lastly, NYHA class may have changed significantly during the long-term follow-up. Unfortunately, this information was not available. Therefore, the main focus of this analysis was NYHA class at the time of device implantation/referral for device therapy. 
Acknowledgements: none

Funding: This work was supported by the following independent institutions: the Toulouse Association for the Study of Rhythm Disturbances; the French Institute of Health and Medical Research; and the French Society of Cardiology. Dr. Lambiase is supported by UCLH Biomedicine NIHR funding.

Disclosures and Conflicts of Interest: Dr. Providencia has received training grant from Boston Scientific, and Sorin Group and a Research Grant from Medtronic. Dr. Babuty has received travel support and clinical study support from Biotronik, Boston Scientific, Medtronic, St. Jude Medical, and Sorin Group. Dr. Sadoul has received personal fees from Biotronik, Boston Scientific, Medtronic, Sorin Group, and St. Jude Medical. Dr. Piot has received consulting honoraria from Medtronic and St. Jude Medical and research grants from Medtronic and Boston Scientific. Dr. Klug has received consultant fees from St. Jude Medical, Medtronic, Sorin Group, Boston Scientific, and Biotronik. Dr. Boveda has received consulting fees from Medtronic, Boston Scientific, and Sorin Group. All other authors have reported that they have no relationships relevant to the contents of this paper to disclose. 


\section{References}

1. Epstein AE, DiMarco JP, Ellenbogen KA, Estes NA 3rd, Freedman RA, Gettes LS, Gillinov AM, Gregoratos G, Hammill SC, Hayes DL, Hlatky MA, Newby LK, Page RL, Schoenfeld MH, Silka MJ, Stevenson LW, Sweeney MO, Tracy CM, Epstein AE, Darbar D, DiMarco JP, Dunbar SB, Estes NA 3rd, Ferguson TB Jr, Hammill SC, Karasik PE, Link MS, Marine JE, Schoenfeld MH, Shanker AJ, Silka MJ, Stevenson LW, Stevenson WG, Varosy PD; American College of Cardiology Foundation; American Heart Association Task Force on Practice Guidelines; Heart Rhythm Society. 2012 ACCF/AHA/HRS focused update incorporated into the ACCF/AHA/HRS 2008 guidelines for device-based therapy of cardiac rhythm abnormalities: a report of the American College of Cardiology Foundation/American Heart Association Task Force on Practice Guidelines and the Heart Rhythm Society. J Am Coll Cardiol 2013;61:e6-75.

2. Priori SG, Blomström-Lundqvist C, Mazzanti A, Blom N, Borggrefe M, Camm J, Elliott PM, Fitzsimons D, Hatala R, Hindricks G, Kirchhof P, Kjeldsen K, Kuck KH, Hernandez-Madrid A, Nikolaou N, Norekvål TM, Spaulding C, Van Veldhuisen DJ; Authors/Task Force Members; Document Reviewers. 2015 ESC Guidelines for the management of patients with ventricular arrhythmias and the prevention of sudden cardiac death: The Task Force for the Management of Patients with Ventricular Arrhythmias and the Prevention of Sudden Cardiac Death of the European Society of Cardiology (ESC) Endorsed by: Association for European Paediatric and Congenital Cardiology (AEPC). Europace 2015;17:1601-1687.

3. Bardy GH, Lee KL, Mark DB, Poole JE, Packer DL, Boineau R, Domanski M, Troutman C, Anderson J, Johnson G, McNulty SE, Clapp-Channing N, Davidson-Ray LD, Fraulo ES, Fishbein DP, Luceri RM, Ip JH; Sudden Cardiac Death in Heart Failure Trial (SCD-HeFT) Investigators. Amiodarone or an implantable cardioverter-defibrillator for congestive heart failure. $N$ Engl J Med 2005;352:225-237. 
4. Moss AJ, Zareba W, Hall WJ, Klein H, Wilber DJ, Cannom DS, Daubert JP, Higgins SL, Brown MW, Andrews ML; Multicenter Automatic Defibrillator Implantation Trial II Investigators. Prophylactic implantation of a defibrillator in patients with myocardial infarction and reduced ejection fraction. N Engl J Med 2002;346:877-883.

5. Hohnloser SH, Kuck KH, Dorian P, Roberts RS, Hampton JR, Hatala R, Fain E, Gent M, Connolly SJ; DINAMIT Investigators. Prophylactic use of an implantable cardioverterdefibrillator after acute myocardial infarction. N Engl J Med 2004;351:2481-2488.

6. Steinbeck G, Andresen D, Seidl K, Brachmann J, Hoffmann E, Wojciechowski D, KornacewiczJach Z, Sredniawa B, Lupkovics G, Hofgärtner F, Lubinski A, Rosenqvist M, Habets A, Wegscheider K, Senges J; IRIS Investigators. Defibrillator implantation early after myocardial infarction. N Engl J Med 2009;361:1427-1436.

7. Bristow MR, Saxon LA, Boehmer J, Krueger S, Kass DA, De Marco T, Carson P, DiCarlo L, DeMets D, White BG, DeVries DW, Feldman AM; Comparison of Medical Therapy, Pacing, and Defibrillation in Heart Failure (COMPANION) Investigators. Cardiac-resynchronization therapy with or without an implantable defibrillator in advanced chronic heart failure. $N$ Engl J Med 2004;350:2140-2150.

8. Moss AJ, Hall WJ, Cannom DS, Klein H, Brown MW, Daubert JP, Estes NA 3rd, Foster E, Greenberg H, Higgins SL, Pfeffer MA, Solomon SD, Wilber D, Zareba W; MADIT-CRT Trial Investigators. Cardiac-resynchronization therapy for the prevention of heart-failure events. $N$ Engl J Med 2009;361:1329-1338.

9. Chauvin M, Frank R, Le Heuzey JY, Barnay C, Cazeau S, Djiane P, Guenoun M, Leenhardt A, Mabo P, Sadoul N; Groupes de stimulation cardiaque et de rythmologie de la Société française de cardiologie. Recommendations concernant l'implantation et la surveillance des défibrillateurs automatiques implantables. Arch Mal Coeur Vaiss 2004;97:915-919. 
10. Vandenbroucke JP. The making of strobe. Epidemiology 2007;18:797-799.

11. Miller RJ, Howlett JG, Exner DV, Campbell PM, Grant AD, Wilton SB. Baseline Functional Class and Therapeutic Efficacy of Common Heart Failure Interventions: A Systematic Review and Meta-analysis. Can J Cardiol 2015;31:792-799.

12. Salukhe TV, Briceno NI, Ferenczi EA, Sutton R, Francis DP. Is there benefit in implanting defibrillators in patients with severe heart failure? Heart 2010;96:599-603.

13. The MERIT-HF Investigators. Effect of metoprolol CR/XL in chronic heart failure: Metoprolol $\mathrm{CR} / \mathrm{XL}$ Randomised Intervention Trial in Congestive Heart Failure (MERIT-HF). Lancet 1999;353:2001-2007.

14. Kreuz J, Balta O, Linhart M, Fimmers R, Lickfett L, Mellert F, Nickenig G, Schwab JO. An impaired renal function and advanced heart failure represent independent predictors of the incidence of malignant ventricular arrhythmias in patients with an implantable cardioverter/defibrillator for primary prevention. Europace 2010;12:1439-1445.

15. Zareba W, Piotrowicz K, McNitt S, Moss AJ; MADIT II Investigators. Implantable cardioverter-defibrillator efficacy in patients with heart failure and left ventricular dysfunction (from the MADIT II population). Am J Cardiol 2005;95:1487-1491.

16. Ng AC, Bertini M, Borleffs CJ, Delgado V, Boersma E, Piers SR, Thijssen J, Nucifora G, Shanks M, Ewe SH, Biffi M, van de Veire NR, Leung DY, Schalij MJ, Bax JJ. Predictors of death and occurrence of appropriate implantable defibrillator therapies in patients with ischemic cardiomyopathy. Am J Cardiol 2010;106:1566-1573.

17. Moss AJ, Greenberg H, Case RB, Zareba W, Hall WJ, Brown MW, Daubert JP, McNitt S, Andrews ML, Elkin AD; Multicenter Automatic Defibrillator Implantation Trial-II (MADIT-II) 
Research Group. Long-term clinical course of patients after termination of ventricular tachycarrhythmia by an implanted defibrillator. Circulation 2004;110:3760-3765.

18. Poole JE, Johnson GW, Hellkamp AS, Anderson J, Callans DJ, Raitt MH, Reddy RK, Marchlinski FE, Yee R, Guarnieri T, Talajic M, Wilber DJ, Fishbein DP, Packer DL, Mark DB, Lee $\mathrm{KL}$, Bardy GH. Prognostic importance of defibrillator shocks in patients with heart failure. $N$ Engl J Med 2008;359:1009-1017.

19. Dorian P, Hohnloser SH, Thorpe KE, Roberts RS, Kuck KH, Gent M, Connolly SJ. Mechanisms underlying the lack of effect of implantable cardioverter-defibrillator therapy on mortality in high-risk patients with recent myocardial infarction: insights from the Defibrillation in Acute Myocardial Infarction Trial. Circulation 2010;122:2645-2652.

20. Goldenberg I, Vyas AK, Hall WJ, Moss AJ, Wang H, He H, Zareba W, McNitt S, Andrews ML; MADIT-II Investigators. Risk stratification for primary implantation of a cardioverterdefibrillator in patients with ischemic left ventricular dysfunction. I Am Coll Cardiol 2008;51:288-296.

21. van Rees JB, Borleffs CJ, van Welsenes GH, van der Velde ET, Bax JJ, van Erven L, Putter H, van der Bom JG, Schalij MJ. Clinical prediction model for death prior to appropriate therapy in primary prevention implantable cardioverter defibrillator patients with ischaemic heart disease: the FADES risk score. Heart 2012;98:872-877. 
Figure 1 - Mortality and incidence of appropriate ICD interventions during follow-up.

Legend: NYHA - New York Heart Association functional class. Adjustment performed for baseline differences (atrial fibrillation, left ventricular ejection fraction, ischemic cardiomyopathy and estimated glomerular filtration rate < $60 \mathrm{ml} / \mathrm{min})$.

Figure 2 - Causes of death (relative \%) according to NYHA functional class.

Legend: NYHA - New York Heart Association functional class; ICD - implantable cardioverter defibrillator; CV cardiovascular. 